\title{
A Transportation Risk Assessment Tool for Analyzing the Transport of Spent Nuclear Fuel and High-Level Radioactive Waste to the Proposed Yucca Mountain Repository
}

\author{
McSweeney, Thomas, Winnard, Thomas, Ross, Steven B., Best, Ralph E.
}

The Yucca Mountain Draft Environmental Impact Statement (DEIS) analysis addressed the potential for transporting spent nuclear fuel and high-level radioactive waste from 77 origins for 34 types of spent fuel and high-level radioactive waste, 49,914 legal weight truck shipments, and 10,911 rail shipments. The analysis evaluated transportation over 59,250 unique shipment links for travel outside Nevada (shipment segments in urban, suburban or rural zones by state), and 22,611 links in Nevada. In addition, the analysis modeled the behavior of 41 isotopes, 1091 source terms, and used 8850 food transfer factors (distinct factors by isotope for each state). The analysis also used mode-specific accident rates for legal weight truck, rail, and heavy haul truck by state, and barge by waterway. This complex mix of data and information required an innovative approach to assess the transportation impacts. The approach employed a Microsoft ${ }^{\circledR}$ Access database tool that incorporated data from many sources, including unit risk factors calculated using the RADTRAN IV transportation risk assessment computer program.

Using Microsoft ${ }^{\circledR}$ Access, the analysts organized data (such as state-specific accident and fatality rates) into tables and developed queries to obtain the overall transportation impacts. Queries are instructions to the database describing how to use data contained in the database tables. While a query might be applied to thousands of table entries, there is only one sequence of queries that is used to calculate a particular transportation impact. For example, the incident-free dose to offlink populations in a state is calcuiated by a query that uses route segment lengths for each route in a state that could be used by shipments, populations for each segment, number of shipments on each segment, and an incident-free unit risk factor calculated using RADTRAN IV. In addition to providing a method for using large volumes of data in the calculations, the queries provide a straight-forward means used to verify results.

Another advantage of using the MS Access database was the ability to develop query hierarchies using nested queries. Calculations were broken into a series of steps, each step represented by a query. For example, the first query might calculate the number of shipment kilometers traveled through urban, rural and suburban zones for all states. Subsequent queries could join the shipment kilometers query results with another table containing unit risk factors calculated using RADTRAN IV to produce radiological impacts.

Through the use of queries, impacts by origin, mode, fuel type or many other parameters can be obtained. The paper will show both the flexibility of the assessment tool and the ease it provides for verifying results. 